\title{
Collaborative Pharmacy Student Learning Outline for Mobile Atmosphere
}

\author{
Dr. Mohamed F. AlAjmi, \\ King Saud University, Riyadh, \\ Saudi Arabia
}

\author{
Shakir Khan (Corresponding Author) \\ Researcher at King Saud University, \\ Riyadh Saudi Arabia Nationality Indian
}

\begin{abstract}
- the idea of this research is for the concern of Collaborative learning based mobile factors by applying via pharmacy students of the college. We focus on three features, computer mutual learning, learning process module, and student learning mode. In this paper, studentfocused instruct module, student edge section, teacher interface section, learner section, solution problem section, curriculum section, control section, and diagnose section are planned. This system permits students to be sustained with a real time approach, non-real time approach, mixture approach. The devices used contain smart phone, PDAs, mobile devices, transportable computers and tablet PDAs. This system is to become a more capable student learning environment so that student can get student's learning done more efficiently. The development of a collaborative learning combines the advantages of an adaptive learning environment with the advantages of mobile telecommunication and the suppleness of mobile devices.
\end{abstract}

Keywords-collaborative learning; mobile environment; real time approach; non-real time approach; mixture approach; lecture section; interface section; learner section; diagnose section

\section{INTRODUCTION}

In current years, speedily increased mobile telecommunication and mobile devices utilize are extended and educational approaches are followed to open education via incorporated multimedia tele-learning system in cyberspace. The fast mobile technological development and the wider ease of access of high-quality telecommunications are advantage to bring about an important revolution in e-learning. The growth of learning lecture based on this kind of technology as graphics, image, voice, and video has turned into the media for collaborative learning. Collaborative learning plays a significant role of within the mobile learning, so mutual learning system must be designed to convince several key requirements. These important requirements are resultant from multimedia application progress platform base which is interfaced with CSCW (Computer-Supported Cooperative Work) technology, and education engineering [12].

M-learning is frequently thought of as a structure of elearning, but it would be more properly defined as a part, or sub-level, of e-learning. M-learning is a new phase in the progress of e-learning that resides within its limitations [9]. Mlearning is not just wireless or Internet standed e-learning but should consist of the anytime/any place idea without stable connection to physical networks. The benefits of m-learning in comparison to e-learning include: flexibility, cost, size, ease of use and timely application. The devices utilized include smart phone, mobile phones, PDAs, portable computers and tablet PDAs [9]. The mechanisms of the mobile learning environment are mobile microprocessors, server module, movable telecommunication, and mobile sensors.

M-learning is more than besides the latest educational idea or method. Learning takes place not immediately in classrooms, but in the house, the place of work, the park, the library, museum, and in our daily connections with others [2]. A student is free to begin a class at several times within a specified time frame. This system is to become a more competent student learning environment so that student can obtain student's learning done more professionally. In collaborative learning, there are three approaches; in case of a real-time approach, this system designed to comprise audio/video/chatting control to perform m-learning. The most important aim of real-time approach is to give students with a user friendly environment to add-on classroom experience. In case of non real-time approach, the system is considered to contain a lecture editor to perform collaborative learning.

We focus on three features, computer-supported collaborative learning, learning process section, and student learning approach. This collaborative learning builds up a lecture section, student interface section, teacher interface section, learner section, solution problem section, curriculum section, control section, and diagnose section to extend a checking and contributing technology in an learning environment. In reality it seeks to improve it by giving the audio/video/chatting for non-real time and on-going communication. It wants to be appropriately guided or monitored in order to create the favored results.

\section{ARRANGEMENT OF MOBILE ATMOSPHERE}

M-learning is a learning atmosphere supporting student learning using digital media in a geologically scattered environment. This system is explained with the following elements: content creator, service contributor, and wire-less network. Many devices such as PDA and smart phones are prepared with unusual hardware and software constraints. Hardware controls can be utilized to explain device hardware competence such as platform, CPU speed, screen size, memory size and resolution. Software control can be utilized to explain device software competence such as operating system, playable media type, browser and resolution [17]. 


\section{A. Mechanism of the mobile environment}

Figure 1 shows the mechanism of the mobile learning environment. Mechanism of the mobile learning environment includes [3] [9]. Mobile microprocessors with memory will be rooted in every object and device. The information each C.P.U will be hold about the entity. When a student moves toward, the sensor senses their existence and will create transmitting information to the student's PDA and smart phone.

Server section will comprise the server, the learning strategies unit and a Database. The server controls the network resources. The instructive strategies unit permits for the application of strategies to strengthen and assist student understanding via communication and feedback. It analyses student reply to small quiz questions and proceeds more information or information in an unusual form when required. DB keeps all the data about the objects/devices, the users and the communications that happen.
Mobile telecommunication technology will be in the structure of Bluetooth and WiFi. The Bluetooth has weak power of signal, uses little control and wrap a relatively short distance. Its low power using up and capability to communicate with other devices is exceptionally beneficial when using handheld devices. The WiFi has a range and speed which surpasses that of Bluetooth. It is well-matched with any brand of Access Point and client hardware built to the WiFi standard.

Mobile sensors will be utilized to detect any modification in the environment. These will be located neighboring to the objects/devices and will be used to identify the presence of students. The sensors used will include closeness, to detect movement, and light, to notice changes in light strength. The section follows and locates each student within the m-space with the use of sensors. When a student moves toward an object, sensors wirelessly contact the intranet and mobile learning environment and broadcast information about the object.
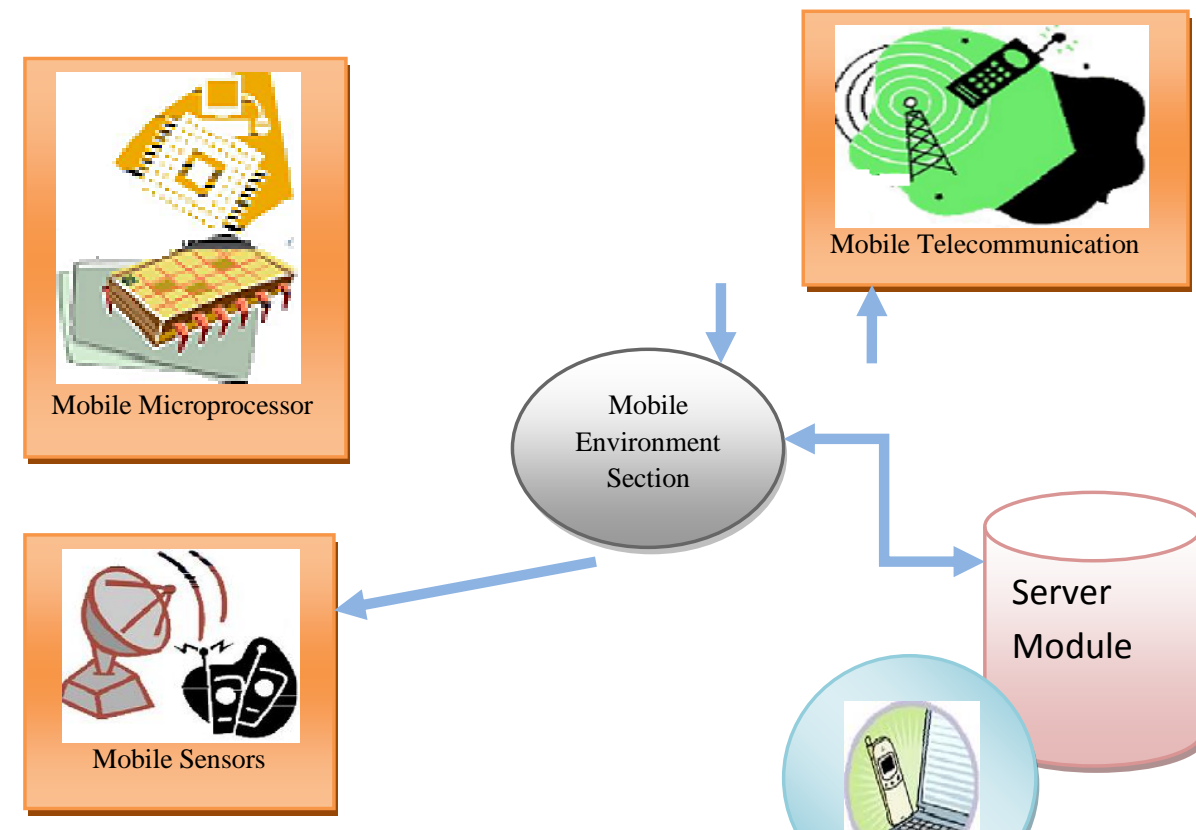

Fig. 1. "Mechanism of the mobile learning environment"

\section{B. Design}

Mobile Learning is explained with the following fundamentals [3]: content creator, service provider, and wireless set of connections. Content creator presents data in an expressive and informative way.

The growth of learning content based on such technology like graphics, voice, image and video has turned out to be the resource for student learning service. Content creator provides a variety of function: generating and modifying a database structure, and adding, editing, deleting, and getting back records via querying and or working with various tables.

Content creator also includes producing links, producing tables, taking data. Planned arrangement of lecture note is found by teacher. The instructional objectives, process, and methodologies are applied to the lecture note. A lecture note is extremely polished student-centered a lecture note methodology guarantees considerate of subject idea and features. The teacher set up a lecture note using a variety of tools to generate, edit and format an article and a lecture note is reserved in the server. Content creator also gives an editor form makes smooth the progress of anyone. It is probable to create lecture material by the document editor. In case of nonreal time, content creator gives a subject learning content, feedback, and learning phase on demand from the student. Proper links has to be given as the reference materials. Links and indication to internal and external websites can also be given.

Service provider consists of various approaches: real time learning approach, non-real time learning approach, and 
mixture learning approach. Service provider planned the execution of student learning system between student and educator in mobile environment. Service provider maintains the formation and deletion of the service entity for media utilize and sharing between remote students. Media Services edge the service by hardware restraint. During lecture time, the system maintains audio/video/chatting control for efficient communication of the students with the teacher. Wire-less network is in charge of data moving among mobile devices in scattered environment. Wireless network generate the network correlation, which overall form a collaboration work, destroys and carries out the functions controlling the QOS by cracking the network load. Wireless network reproduces multiple-point connection using stream and several applications share the same network connection.

\section{Aspects of mobile learning}

In this paper, we will focus on mobile learning, mobile devices-supported student learning phase. The main features of mobile learning are shown as follows [3] [23].

Reliability: Students can never drop their study unless it is persistently deleted. In addition, all the learning processes are recorded endlessly.

Convenience: Students have access to their files,

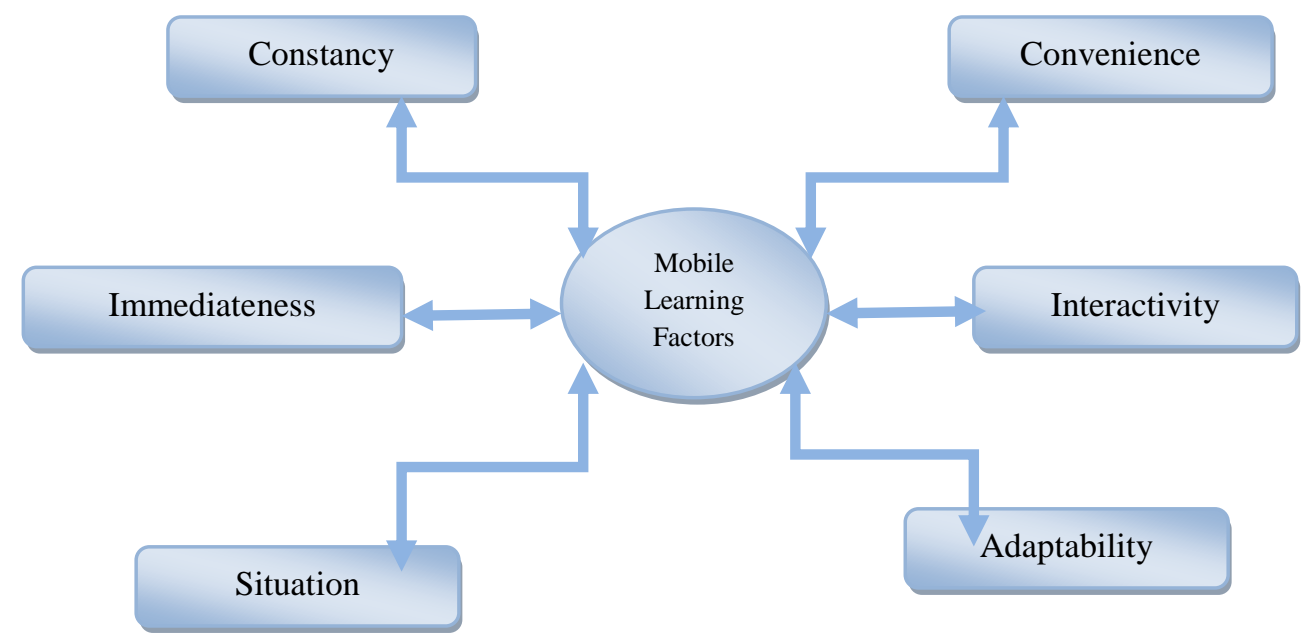

documents, data, or videos from any place. This information is given based on their needs. Therefore, the learning concerned is self-directed adult learner.

Immediateness: Students can get any information immediately at any location. Therefore students can solve problems promptly. Otherwise, the student may record the questions and check for the answer later.

Interactivity: Students can interrelate with experts, teachers, or peers in the way of synchronous or asynchronous communication. Hence, the teachers are more accessible and the knowledge is more available at any time and at any place as well.

Circumstances: The learning could be implanted in our daily life. The problems came across as well as the knowledge necessary are all presented in the nature and authentic forms. It assists students and notices the features of difficult situations that create particular actions relevant.

Flexibility: Students can get the correct information at the exact place with the right way. Moreover, mobile learning can be CSCW environments that target on the social knowledge building and sharing. Figure 2 shows the main factors of mobile learning.

Fig. 2. "The main factors of mobile learning"

\section{Collaborative LEARNING}

Collaborative learning is a variety of approaches in education that engage joint logical effort by students or students and teachers. Collaborative learning refers to methodologies and environments in which students connect in a general lecture in which each person depends on and is responsible to each other. Groups of students learn together in searching for understanding, significance or solutions of their study such as a product. The mode is closely linked to cooperative learning. Collaborative learning behavior can consist of collaborative writing, group projects, and other behavior. Collaborative learning has taken on various configurations [25]. The first is collaborative learning for the self-sufficient adult learner, youth going to collaboration, another configuration of self-sufficient organizing. Computer- supported collaborative learning has come out as a novel educational model among researchers and practitioners in a number of fields, together with cognitive sciences, computer engineering, and sociology. Collaborative Learning also has an exact meaning in the environment of LMS (Learning Management Systems). In this environment, collaborative learning refers to a collection of tools which students can use to help, or be helped out by others. Such tools consist of chat, discussion threads, and application distribution among several others. Particularly appropriate to e-learning where developers can distribute and put together knowledge into courses in a collaborative atmosphere. Knowledge of a single subject can be pulled together from remote places via software systems.

\section{A. Category of Collaborative Learning}

Irregular learning collections are grouping of students 
within a single class gathering. We can also form cluster of five students to crack a problem or create a question. Irregular groups systematize at any time in a class of any number of students to check on students' thought of the material, to give students a chance to apply what they are getting through this type of learning, or to give a transform of speed. Regular learning collections are teams well-known to finish a specific task, such as to carry out a class experiment, writing a report, performs a project.

These groups may finish their work in a particular class session or over several weeks. Normally, students work together until the task is completed, and their project is ranked. Group of students are long-term with regular membership whose foremost responsibility is to provide members with support, encouragement, and assist in finishing course necessities and assignments. Class groups also notify their members about lectures and coursework when student has missed a lecture. Bigger the class and the more difficult the subject matter, the more important class teams can be. The proposals below are considered to help you set up unbalanced learning clusters and class teams [25] [26].

\section{B. Components of Collaborative Learning}

Primarily student interface section monitors the student's procedures, informing other agents when required and providing access to system resources. This component controls the access to the learner reproduction and passes to the learner information about the entire learning atmosphere.

Lecture component proposes the most appropriate problem/situation to the student, together with learning goals and the level of knowledge. Also the tutoring agent makes a decision on a specific strategy. Moreover, its didactical decisions are based on students' ideas. To achieve tutoring goals, it is able to initiate the lower-level element whenever a diagnosis is required and, once diagnosis phase is ended, it plans communications with other learners.

Teacher interface module is a mediator linked with the teacher's interface. This component controls the admission to the teacher's KB and brings to the student information about the complete learning atmosphere. This component intervene interface elements related to: contact with other teachers, update of novel activities to the students, sharing of such activities to students, and control of work done by students. Information $\mathrm{KB}$ is in charge for getting back and filtering information from particular sources that can vary from the learning resources and experiences available in the system to the whole Web. The communication component control the communication with other mediators, including influential message, sending out communication, and receiving and interpreting communication.

In Control component, learners select operators, authenticate actions, and authenticate the final result. Control elements are keen when attached to the reality that the learner makes declaration based on somewhat on the screen and utilizes this information to take and validate choices.
Diagnose component is in charge for replying other component queries. The strategy component considers entire solution paths and recommends advice only when the student finishes the problem. The clearest issue that comes up when tutoring mediator exists in a system is what to do when the tutoring mediator is not agreed. In the modules offered here, we might have circumstances where teacher approach module needs to present a communication at the same time.

Learner component is planned to meet the requirements of the learner. The learner representation is also used to observe if the information has already been educated to the student.

Learner DB consist of a management constituent which is in charge for organizing the learners, for instance passing on login names and passwords, and running two databases accessible in the system, that is the learner's history database and the database with the verified learning knowledge. A third database controls the learning profile of the learners, but this database is contacted by the learner elements of each learner.

KB includes a practical knowledge base and linked exercises to facilitate an efficient evaluation of the possible use of the system within a syllabus. Each tutor has its own specific tutor's information base and also succeeds to global knowledge from a common fact.

Solution Problem section becomes fulfilled when the group of problems it represents is there in the atmosphere. The arrangement of the different values these didactical variables could acquire, leads to more or less composite problems, permitting to focus on dissimilar aspects of the learning of indication and most important, allowing the expression of different ideas.

Syllabus module has course information which stands for the target skill and its component sub-skills, and depicts how they are linked. The teacher's common strategy is to present tutoring, ask questions, and assess answers. It generates and updates a student replica based on knowledge of the learner's ordinary language answers to evaluation questions. Figure 3 shows the component of collaborative learning [4] [8].

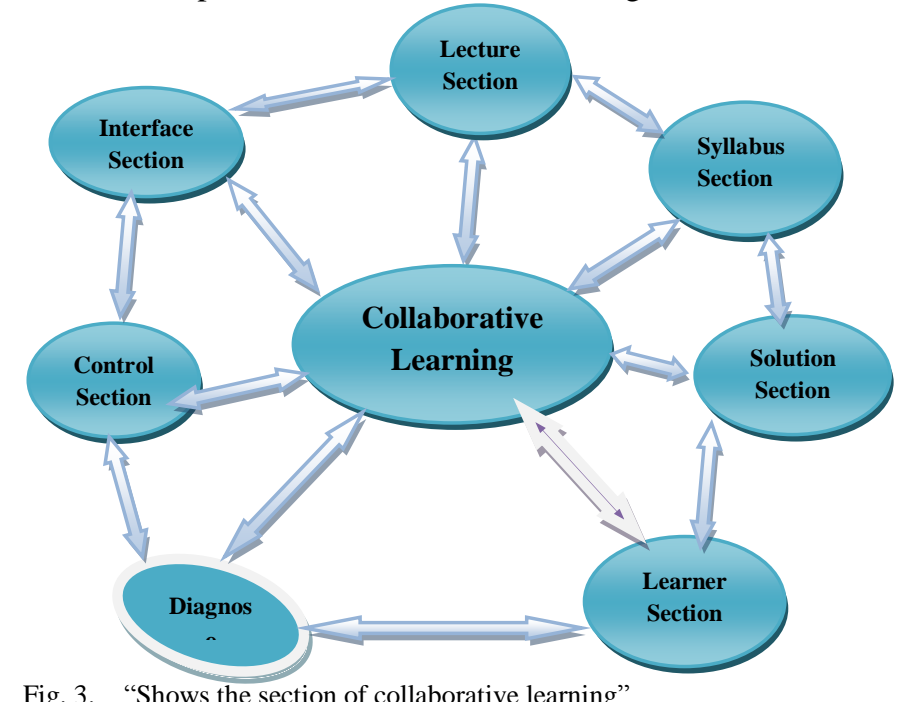

Fig. 3. "Shows the section of collaborative learning" 


\section{APPROACH OF COLLABORATIVE LEARNING}

\section{A. Instantaneous technique}

Real-Time Learning consists of m-learning server, teacher client, and student client. Two customer applications run under Symbian, Palm, iOS, Android, Windowphone7 on smart phone linked to the server. Client atmosphere consists of four components for student coincident learning services [3]: Teacher test information manager, Teacher test monitor, Student information searcher, and Student test manager.

Lecture manager: The teacher sets up a lecture via the various lecture note is reserved in the server. There is the lecture manager that five buttons of top are lecture framework, model lecture frame, lecture registration, lecture remove and lecture start button. The list box of hub is registered education subject list. This window means that the system is innate and simple for students to use.

Tool Manager: This module manages the use of audio and video resource to identify teacher/ students and also allocates who is the turn of speaking, makes a decision and manages suitable resource task according to application of resources. In tool manager, clarification of each module is as follows: Floor module controls the floor among participants, and it consists of video picture windows as many as the number of learners who contribute in the learning session. Video module is utilized for observing the video of remote applicants, and it shows the video image of the applicant who has the floor controls. Shared module is a window shared by all the applicants, and the delivery carried out by the teacher is informed to each applicant.

Searcher Manager: There is the learner information searcher that two buttons of top are check connection and check wait button. First, after input the server site, push the check connection button. The list box of center is a list of recorded education subject. Secondly, after choose the wishing subject list, push the check wait button.

Class manager: Students progress phase will be stored in a database to show student progress and adequate completion. This manager has the lecture note, which is circulated at the beginning. Lecture note is shared and every contributor draws.

\section{B. Non-Instantaneous technique}

Non- real time learning would add to change PDAs/ smart phone with their most important areas in stand-alone approach and non-interactive application. Non-real time learning is a revision of the idea of demand on lecture. Critical attributes of non- real time learning environments are time and place independence and the asynchronous nature of the PDA/smart phone-mediated communication[3][20].

These features mean that students and teachers do not require being online at the same time or put in order to be able to speak with one another. Thus, smart phone-based student education could be made available to students during particular time periods for students to finish at their free time. With simple network access, students could finish the learning from a lab, or remotely from their residence or place of work. Paper form was offered with a further form holding radiobutton questions.

\section{Combination Approach}

In order to increase an efficient mixture learning that achieves the goals of providing education over the Web, it is compulsory to be aware of key instructional features that will add to the development. It also uses the values of cooperative learning to permit student to contribute in the cooperation of meaning resulting from their quiz of content and realistic testing. It also facilitates both teachers and students to interrelate in real-time or non-real-time in remote sites for interactive hypermedia-based education. After the non-real time education phase, students will be capable to put questions, via an audio channel, turn taking being proscribed by the teacher client. Student will also be trained to use toolbar to join to the smart phone and browse Web sites of relate. Using mixture education technology, student will study to improve references by generating live links to a linked file or Website [3].

\section{TECHNOLOGY-BASED LEARNING'S POTENTIAL}

Whereas even ten to fifteen years ago, the mass of TBL depended on transport video tapes or on costly satellite upload and downloads in special sites, most TBL content today is circulated via CD-ROMs or the Internet.

The Internet seizes meticulous guarantee among educational technologies since it without difficulty have room for multiple learning styles and scattered learning representation[27].On the Internet, clients cannot only see all the content from text to movies to music; they can also interrelate with it, change it, generate innovative content, and distribute it back to a wider society. Additionally, the medium is well coordinated to the novel necessities of education and guidance in the knowledge-based financial system.

Just-in- Another important attribute of TBL is that it gives emphasis to 'knowledge solutions' and 'knowledge consequences,' and is appropriate and can be modified. As such it permits for a novel method to incorporate learning with employment. Rather than instructing workers on each possible process that they may require during their functioning lives, in an e-learning or TBL representation, employees have right of entry to the training component for a given development only if and when they call for it, possibly transported via a handheld computer[28]. Additionally, technology is previously in place that permits TBL release systems to expect future information and learning requirements by identifying patterns in knowledge styles and transporting training in large piece as required by the student.

\section{A. Benefits and Challenges}

TBL comes with considerable benefits. Most of all, it presents geographic achieve and a quality of being scalable of training and instructive hard work that face-to-face communication cannot realize. It also presents an extensive variety of learning styles and a chance to track development and calculate outcomes as a faultless part of knowledge. However, as with all skill applications, the utilization of technology in itself creates some innovative challenges. In TBL, the most important difficulty is the digital divide, which still cracks the country into digital haves and digital economically disadvantaged people. Additionally, transferring 
education into a TBL environment produces additional challenges for instructors and teaching designers.

\section{a) Benefits}

There are abundant advantages to TBL in contrast to faceto-face learning. Five of the major benefits are the following:

1) Ease of access, contribution anytime and anywhere release [29-30-31]

2) Teaching that is self-paced and coordinated to the student's requirements [32-33]

3) Complete scalability [34]

4) Timely broadcasting of latest information

5) Smooth and efficient learning release

b) Challenges

The beginning of TBL is not without challenges. They consist of:

1) The "digital divide," caused by low computer literacy rates and lack of right of entry to technology among a few student populations [35-36]

2) "Social loafing," which takes place when learners decrease their attempt in TBL programs, or are disturbed in their challenges to utilize TBL, because of the program's smaller center on personal communications

3) Higher slow destruction rates [37]

4) Long-suffering individuals with disabilities [38]

5) Technology inappropriateness

6) High progress costs

7) Lack of reliability [39]

\section{CONCLUSION}

Collaborative learning is an educational approach to teaching and education that engages groups of student's knowledge together to resolve a problem, complete an assignment, or generate a product. It is during the talk that learning comes to mind [25]. There is countless advancement to collaborative learning. A set of hypothesis about the learning development underlies them all: Learning is a vigorous process whereby students digest the information and narrate this new knowledge to a framework of previous knowledge. Learning needs a test that opens the door for the student to keenly connect his/her peers, and to process and create information rather than just memorize and repeat it. Students gain when exposed to various viewpoints from people with varied backgrounds. Learning accompaniments in a social atmosphere where discussion between learners takes place.

Through this thinker gymnastics, the learner generates a framework and meaning to the discussion. In the collaborative learning environment, the students are tested both socially and emotionally as they pay attention to various perceptions, and are necessary to clear and defend their thoughts. In so doing, the students start to generate their own distinctive conceptual frameworks and not rely only on an expert's or a text's framework. Thus, in collaborative learning surroundings, students have the chance to communicate with peers, present and defend thoughts, exchange diverse thinking, question other conceptual frameworks, and are actively engaged.
Learning is a characteristic of living not of place. We have always been intelligent to learn in different settings other than the reserved classroom, and frequently in a more enjoyable, excellent, and useful way. But, mobile learning gives out to take you back of the need to persistently re-examine how learning takes place and to concentrate to the affordances of new technologies [24]. The idea of this research is for the concern of mobile learning atmosphere based real-time, nonreal time and mixture approach. This paper projected the realization of learning between student and teacher of service contributor in u-space, which is not restricted to traditional learning system.

This system permits students to be maintained with a constancy, convenience, interactivity, situation, immediateness, adaptability. The system is to offer a troublefree to utilize interface, so that the students are motivated to utilize it for their education. We also developed a set of necessities that supported by lecture component, student interface section, teacher interface component, learner module, solution problem component, curriculum component, control module, and diagnose component in order to complete an successful student collaborative learning. Also, the systems has several other rewards, which facilitate learning, PDA/smart phone service, real time, non-real time, mixture mode, high degree of data management and management of attendance[8].

We measured our m-learning system, usability and applicability, and concluded that it can be used for the multimedia PDA/smart phone in m-learning atmosphere. We are also in conflict for a better contest between theoretical frameworks and methods in m-learning research. While these are positively significant considerations, we believed that long-term access would be attained by the potential of contribution real time learning that are free from time and place control[11][12]. The improvement of a collaborative learning combines the advantages of an adaptive learning environment with the advantage of ubiquitous computing and the plasticity of mobile devices [3]. Students have the freedom to study within a learning atmosphere which presents flexibility to their person needs and learning approaches, as well as the flexibility of persistent and low profile computer systems. Collaborative learning practices can be integrated into a typical 50-minute class in a multiplicity of ways. A few require a systematic preparation, such as a long-term project, while others need less preparation, such as pretense a question in the lecture and putting students to talk about their thoughts with their neighbors. Despite of the particular approach taken or how much of the ubiquitous lecture-based course is substituted, the objective is the similar: to shift education from a teacher-centered to a student-centered model. This system is turned out to be a more competent student collaborative learning atmosphere so that student can acquire student's education done more professionally.

\section{ACKNOWLEDGMENT}

The authors acknowledge the support from the Research Center, College of Pharmacy, King Saud University, Riyadh (KSA). 
REFERENCES

[1] A. Martens, "Support cognitive processes in intelligent tutoring systems ", Proc. Of the International Conf. on Cognitive Modeling", Bamberg, Germany, 2003

[2] N. Gaby, \& Z. Dietrich "Intelligent Methods t o Evaluate Solutions of Interactive Calculation Exercises and Model-Based Experiments in Logistics Education", Proceedings of ED-MEDIA, Educational Multimedia and Hypermedia, pp. 521-526, 1996.

[3] J.S. Sung, "U-Learning Model Design based on Ubiquitous Environment", IJAST, Vol 13, 2009.

[4] J.S. Sung, "Application Protocol Design for Collaborative Learning”, IJUNSSET, 2(4), 2009.

[5] C. Y. Chang \& J. P. Sheu, "Design and Implementation of Ad Hoc Classroom and e-Schoolbag Systems for Ubiquitous Learning", Paper presented at the IEEE International Workshop on Wireless and Mobile Technologies in Education, August. 29-30, 2002

[6] G. Zhang, Q. Jin \& M. Lin, “ A Framework of Social Interaction Support for Ubiquitous Learning", Paper presented at the 19th International Conference of Advanced Information Networking and Applications, March 28-30, 2005.

[7] H. Ogata, \& Y. Yano, "Context-Aware Support for Computer-Supported Ubiquitous Learning", Paper presented at the 2nd IEEE International Workshop on Wireless and Mobile Technologies in Education, March 23-25, 2004.

[8] J.S. Sung and D.H. Lim, "Adaptive Tutoring an d Training System Based on Intelligent Agent”, IJMUE,2006,1(3)

[9] J. Vick \& H. J. Jun, “ Ubiquitous learning environment: An adaptive teaching system using ubiquitous technology"

[10] K. Cat and H. Peter, "Designing agents for feedback using the documents produced in learning", International Journal on E-Learning, 4(1), 2005, pp. 21-38.

[11] K. Edwards, M. Newman, J. Sedivy, T. Smith, D. Balfanz, D. K. Smetters, C. Wong \& S. Izadi, "Us ing Speakeasy for Ad Hoc Peer-toPeer Collaboration", Paper presented at ACM 2002 Conference on Computer Supported Cooperative Work (CSCW 2002), November 1620, 2002.

[12] N. Som, \& O. Peter "Making the Most of Practical Experience in Teacher Education With Computer-Supported Collaborative Learning", AACE International Journal of Educational Telecommunications,2(4), pp. 265-278, 1996.

[13] M. Takahata, K.Shiraki, T. Sakane \& Y. Takebayashi, "Sound Feedback for Powerful Karate Training", Paper presented at the International Conference on New Interfaces for Musical Expression, June 3-5, 2004.

[14] N. Haruo, P. H. Kiyoharu, K. Yasufumi, \& M. Shiho, “ Designing Ubiquitous and Universal Learning Situations: Integrating Textbooks and Mobile Devices", Paper presented at the 19th Annual conference o $n$ Distance Teaching and Learning, 2003, August 13-15, 2003.

[15] D. Georgio, D. Giuliano, \& P. Domenico "Tea cher-Learners Cooperation Procedures an innovative Computer-Based Course", Proceedings of ED-MEDIA, Educational Multimedia and Hypermedia, pp. 160-165, 1996.

[16] R. Jeff, L. Neal, R. Charles, L. Candace, Sidner and G. Abigail, "Building a Bridge between Intelligent Tutoring and Collaborative Dialogue Systems", Tenth International Conference on AI in Education, 2001, pp. 592-594.

[17] S. J. H. Yang, "Context Aware Ubiquitous Learning Environments for Peer-to-Peer Collaborative Learning, Educational Technology \& Society, 9 (1), 188-201, 2006.

[18] S. J. H. Yang, Lan,., B. C. W. Wu, B. J. D. \& A. C. N. Chang, " Context Aware Service Oriented Architecture for Web Based Learning", International Journal of Advance learning Technology, 2 (4), retrieved October 25, 2005 from http://www.actapress.com/Content_Of_Journal.aspx?JournalID=63

[19] V. Aleven, B.M. McLaren, I. Roll, and K. Koedinger, "Toward Tutoring
Help Seeking: Applying Cognitive Modeling to Meta-Cognitive Skills", Proc. Of Intelligent Tutoring Systems (ITS), 2004

[20] W. Carine, B. Loris, P. Sylvie and B. Nicolas, "The Baghera project: A multi-agent architecture f or human learning", available at http://julita.usask.ca/Mad muc/Baghera.rtf, 2001.

[21] Z. Cheng, S. Shengguo, M. Kansen, T. Huang, \& H. Aiguo, “ A Personalized Ubiquitous Education Support Environment by Comparing Learning Instructional", P aper presented at the 19th International Conference on Advanced Information Networking and Applications, March, 28-30, 2005.

[22] Z. Yiying, G. Lei, and D. Nicolas, "AGILE: Architecture for AgentBased Collaboration and Interactive Virtual Environments".

[23] Chen et al., Curtis et al., 2002, In Young Scientific Research (2) no. 15700516 from Japan Society for the Promotion of Science.

[24] Young Scientific Research (2) no. 15700516 from Japan Society for the Promotion of Science.

[25] From Wikipedia, the free encyclopedia

[26] From the hard copy book Tools for Teaching by Barbara Gross Davis; Jossey-Bass Publishers: San Francisco, 1993.

[27] Brown, J. S. 2002. Growing up digital. USDLA Journal. Vol. 162

[28] PEW Internet and American Life Project. 2005. Latest Trends. http://www.pewinternet.org/trends.asp

[29] Australian Flexible Learning Framework. 2004a. E-Learning ambulance trainees top the class. Organization Profile and Objective: Ambulance Service of New South Wales. http://pre2005.flexiblelearning.net.au/casestudies/casestudies/nsw_ambo $\underline{\text { s.pdf }}$

[30] Australian Flexible Learning Framework. 2004b. South Australian police uphold the law with e-learning. Organization Profile and Objective: South Australia Police. http://pre2005.flexiblelearning.net.au/casestudies/casestudies/sa_police.p df

[31] Sloan Consortium. 2004. Practice: Web-Based Doctor of Pharmacy Pathway: Expanding Access to Underserved Populations. Sloan Consortium Website. Effective Practices. http://www.sloan-c.org/

[32] Harris, P. 2005. Blended learning fuels sales at Toshiba. Learning Circuits. http://www.learningcircuits.org/2005/nov2005/0511_Toshiba_Harris.ht $\mathrm{m}$

[33] Summerfield, B. 2005. British Airways: The wings of learning. Chief Learning Officer Magazine: MediaTec Publishing. http://www.clomedia.com

[34] Hollis, E. 2004. U.S. Navy: Smooth sailing for education. Chief Learning Officer Magazine. Media Tech Publishing. http://www.clomedia.com/content/templates/clo_casestudies.asp?articlei $\mathrm{d}=376 \&$ zoneid $=9$

[35] National Telecommunications and Information Administration U.S. Department of Commerce: Economics and Statistics Administration. 2002. A Nation Online: How Americans are Expanding their Use of the Internet. http://www.ntia.doc.gov/ntiahome/dn/anationonline2.pdf

[36] 17-Bell, P., P. Reddy, and L. Rainie. 2004. Rural areas and the Internet. Pew Internet \& American Life Project. http://www.pewinternet.org/PPF/r/112/report_display.asp

[37] University of Central Florida. 2006. Distributed Learning Impact Evaluation. http://pegasus.cc.ucf.edu/ rite/impactevaluation.htm

[38] The Rehabilitation Act Amendments of 1998 mandates. http://www.usdoj.gov/crt/508/508law.html

[39] Adams, J. and M. DeFleur. 2005. The acceptability of a doctoral degree earned online as a credential for obtaining a faculty position. The American Journal of Distance Education. http://www.leaonline.com/doi/abs/10.1207/s15389286ajde1902 